\title{
EU CURTO SER SAUDÁVEL
}

\begin{abstract}
Daniela Hobold
Pós-Graduada em Nutrição, Universidade do Extremo Sul Catarinense, danihobold@hotmail.com

Marilda Ghellere

Mestra, Universidade do Extremo Sul Catarinense, marighellere@engeplus.com.br
\end{abstract}

\section{RESUMO}

A equipe do Núcleo de Apoio à Saúde da Família (NASF), de Nova Veneza (SC), foi procurada pela professora de Educação Física, da Escola Municipal Bairro Bortolotto, localizada no mesmo município, preocupada com o alto índice de excesso de peso entre seus alunos, na faixa etária de 12 a 14 anos. Anualmente, a profissional realiza avaliaçáo antropométrica nos estudantes, porém os dados são arquivados e nada é feito em relação àqueles que apresentam alteraçóes. Ao ter em vista que a obesidade é fator de risco para várias doenças crônicas não transmissíveis, o aumento da prevalência de sobrepeso e obesidade, em idades cada vez mais precoces, justifica a preocupação de profissionais de saúde. Vários fatores são importantes na gênese da obesidade, como os genéticos, fisiológicos e metabólicos. No entanto, os fatores que poderiam explicar este crescente aumento do número de indivíduos obesos parecem estar mais relacionados às mudanças no estilo de vida e aos hábitos alimentares. Além de trazer várias problemáticas à saúde física, a obesidade ainda acarreta prejuízos na autoimagem e profundas repercussóes psicossociais, especialmente graves, por ser a adolescência uma fase de transição e de mudanças corporais. Ao considerar que os resultados efetivos são vistos em longo prazo e que o próprio tratamento tem 
longa duração, o vínculo do paciente à equipe é fundamental e, por ser a obesidade de etiologia multifatorial, faz-se extremamente importante incluir em seu tratamento uma abordagem multidisciplinar. Nesta experiência, foi utilizado o método de trabalho em grupo, haja vista que estudos mostram que a abordagem por meio de grupo apresenta resultados positivos, frente a essa problemática. As sessóes de grupo constituem um espaço de partilha para as diferentes compreensôes da própria situação, de aprendizagem de estratégias e de aquisição de competências na interação com outro. O objetivo principal deste trabalho foi promover o resgate de hábitos saudáveis em adolescentes pertencentes à Escola Municipal Bairro Bortolotto, por meio de açóes educativas em equipe multidisciplinar. $\mathrm{O}$ trabalho descrito teve como público-alvo os adolescentes provenientes da Escola Municipal Bairro Bortolotto, entre 12 a 14 anos, que, após passarem por avaliação antropométrica, tiveram resultados de Índice de Massa Corporal (IMC) para idade igual ou superior ao percentil 97. Ao término da atividade, foram selecionados dez participantes. Após a avaliação inicial, cada aluno realizou uma avaliação médica para verificar a aptidão para a prática de atividades físicas e recebeu uma cópia do Termo de Consentimento Livre e Esclarecido, devolvendo-o assinado pelos pais. A equipe do NASF elaborou um cronograma de atividades incluindo profissionais pertencentes à Estratégia Saúde da Família (ESF), de forma a reunir um conjunto de especialistas em diversas áreas, trabalhando em equipe para atingir o objetivo proposto. As atividades educativas do grupo "Eu Curto Ser Saudável” foram realizadas na Unidade de Saúde do Bairro Bortolotto, em dez encontros, uma vez por semana, com 2 horas de duração cada. Foram utilizados recursos próprios do local, além dos materiais específicos para cada técnica aplicada nos encontros. Simultaneamente foram realizados dois encontros semanais, com 2 horas de duração, durante 16 semanas, com o profissional de Educação Física para a prática de exercícios ao ar livre e nas instalaçóes pertencentes ao Centro de Referência de Assistência Social (CRAS) de Nova Veneza (SC). Também foram realizadas atividades externas, acompanhadas pela equipe multidisciplinar, tais como visitas a supermercado e restaurantes, bem como cortesias para os participantes em saláo de beleza e atividades subsidiadas por parceria com o comércio local. A metodologia de trabalho se fez 
por meio de açóes educativas que visavam compartilhar reflexôes e informaçôes acerca do cultivo de hábitos de vida saudáveis. Participaram dos encontros a psicóloga, o profissional de Educação Física, nutricionista, enfermeira e odontólogo, que utilizaram diversos recursos para execução das atividades, tais como dinâmicas de grupo, jogos, recortes, colagens, desenho, uso de massa de modelar, músicas, passeios de estudo, filme, entre outros. $\mathrm{O}$ trabalho teve duração de 84 horas, entre os meses de junho a outubro de 2013 . O primeiro encontro ocorreu com a presença dos pais, quando foi apresentado o projeto, cronograma de atividades, sensibilização sobre o tema e importância do apoio e comprometimento familiar. Os demais foram iniciados com atividades de socialização entre os participantes, a fim de estabelecer um clima facilitador, seguidos de técnicas que buscavam o autoconhecimento, autoestima, motivação e conhecimento de seus hábitos alimentares. Foram trabalhadas as ansiedades, os medos e os sentimentos associados ao comer. Também foram realizadas reflexóes sobre responsabilidade, ambivalência, mudança de pensamento e mudança de hábitos sociais e em casa, além de estratégias de enfrentamento. Paralelamente às técnicas comportamentais, foram aplicadas atividades de educação nutricional, em que cada participante elaborou seu diário alimentar, conheceu "os dez passos para uma alimentação saudável”, construiu com o restante do grupo a pirâmide alimentar, dentre outras. Ao grupo, foi oportunizado conhecer sobre a composição dos alimentos, além de aprender sobre montagem de um prato de alimentação saudável, de forma lúdica, para, posteriormente, em visita a restaurante, colocar em prática os conhecimentos adquiridos sobre as escolhas que formavam uma refeição saudável. $O$ grupo também visitou uma horta e fez visita ao supermercado, aprendendo sobre a escolha de vegetais, além de treinar a leitura de rótulos. Essas atividades visaram buscar autonomia para escolhas alimentares mais saudáveis. Foi discutida a importância da higiene corporal e bucal. Como complementação da parte teórica e incentivo à prática, os participantes ganharam cortesia em saláo de beleza para corte de cabelos, escova e manicure. O encerramento das atividades ocorreu com depoimentos sobre a experiência vivenciada e confraternização em uma pizzaria local, onde os participantes tiveram a oportunidade de fazer escolhas alimentares conscientes, não menos saborosas ou saudáveis. Entre as atividades realizadas, a visita à horta causou gran- 
de euforia no grupo, inclusive despertou o interesse sobre o cultivo de hortas domiciliares. A atividade de construção da pirâmide alimentar, por meio de recortes, também despertou muito interesse, pois permitiu que os envolvidos conhecessem a composição dos alimentos industrializados. Causou bastante impacto a técnica de demonstração das quantidades de açúcar e de óleo presentes em produtos, como refrigerante, batatas de pacotes, biscoitos recheados e outros alimentos processados. Atividades por meio de dinâmicas, a fim de averiguar a satisfação com o próprio corpo, autoestima, autoconhecimento, foram momentos especiais em que os participantes puderam expressar e compartilhar suas alegrias, tristezas, dificuldades e vitórias, mobilizando todos os participantes. Todas foram experiências gratificantes e motivadoras para os jovens e para os profissionais da saúde, pois, ao término do trabalho, evidenciaram-se melhoras significativas em relação à satisfação corporal e ao desejo de mudança entre os participantes. Todas as técnicas utilizadas procuraram valorizar o saber individual e instrumentalizá-los para a valorização de sua autonomia, pois, assim, poderiam, com o tempo, transformar a sua realidade e a si próprios. Chamou bastante à atenção dos profissionais o fato de muitos pais de participantes trabalharem em período noturno e a maneira de como isso influenciava negativamente sobre os hábitos alimentares e de estilo de vida cultivados no lar. Verificou-se também que o comprometimento da família e o reconhecimento que esta dava ao tratamento da obesidade contribuíram para sucesso das açóes propostas durante a realização do trabalho. Ao considerar que os pais e/ou responsáveis são agentes formadores dos hábitos alimentares e de estilo de vida dos filhos, o conhecimento acerca de nutrição, apoio emocional e importância que eles dispensam à prática de atividades físicas foi fator determinante na adesão ao trabalho proposto, assim como em seus resultados.

Palavras-chave: Obesidade na Adolescência; Equipe Multidisciplinar; Trabalho em Grupo.

\section{INSTITUIÇÃO FINANCIADORA}

Prefeitura de Nova Veneza (SC). 